\title{
Magnetoelectric interaction phenomena in materials
}

\author{
S V SURYANARAYANA \\ Materials Research Laboratory, Department of Physics, Osmania University, Hyderabad \\ 500007 , India
}

\begin{abstract}
Following the phenomenological approach of Landau and Lifshitz the existence of linear magnetoelectric effect in antiferromagnetic $\mathrm{Cr}_{2} \mathrm{O}_{3}$ was predicted by Dzyaloshinskii which was later experimentally confirmed by Astrov and Folen et al. Magnetoelectric phenomenon has been observed in several single-phase materials in which simultaneous electric and magnetic ordering coexists and in two-phase composites in which the participating phases are the ferroelectric and magnetic. The author's group has recently undertaken a systematic study of the preparation, characterization and detection of the $(\mathrm{ME})_{H}$ output in a few single-phase materials and two-phase composites. This article describes the magnetoelectric phenomenon in general and recent work carried out in the author's group.
\end{abstract}

Keywords. Magnetoelectric; ferroelectric; anti-ferromagnetic; composite.

\section{Introduction}

The consideration and analysis of interactions between various subsystems in a crystal forms an important branch of contemporary condensed matter physics. In a variety of materials several new effects have been discovered on the basis of interactions between subsystems in a crystal. In some insulating materials, an external magnetic field can induce electric polarization and an external electric field induces changes in magnetization. Such a phenomenon is called the magnetoelectric (ME) effect. The ME effect observed in some insulating materials offers a challenge to both experimental and theoretical scientists, since the materials showing the ME effect belong to an entirely new class.

In the last century Curie (1894) presumed the existence of $\mathrm{ME}$ effect in some crystals. The statement of Curie that the symmetry conditions show us that it would be possible for asymmetric molecular body to polarise directionally when one places it in a magnetic field is historic. On the basis of the symmetry considerations Landau and Lifshitz (1957) came to the conclusion that the ME effect can exist, in principle, in a magnetically ordered crystal. The starting point for research on an actual crystal was marked by the theoretical prediction of occurrence of $\mathrm{ME}$ effect by Dzyaloshinskii (1959) in the antiferromagnetic $\mathrm{Cr}_{2} \mathrm{O}_{3}$. Shortly after this, Astrov $(1960,1961)$ and Folen et al (1961) reported the experimental observation of $(\mathrm{ME})_{E}$ and $(\mathrm{ME})_{H}$ in $\mathrm{Cr}_{2} \mathrm{O}_{3}$.

As mentioned earlier, the ME phenomenon is due to magnetic and electric interaction in certain crystals. From simple thermodynamic principles this could be expressed in power series in terms of external magnetic field $\mathrm{d} H$ and the electric field $\mathrm{d} E$ as

$$
F=F_{0}-P_{0} \cdot \bar{E}-M_{0} \cdot \bar{H}-1 / 2 \chi_{i j}(E) \cdot \bar{E}_{i} \bar{E}_{j}-1 / 2 \chi_{i j}(H) \bar{H}_{i} \bar{H}_{j}-\alpha_{i j} \bar{E}_{i} \bar{H}_{j} \ldots,
$$


where $F$ is the total Gibbs free energy and $F_{0}$ the free energy independent of $E$ and $H, \chi(E)$ and $\chi(H)$ are electric and magnetic susceptibility tensors, and $\alpha_{i j}$ is the magnetoelectric tensor (Schmid 1965; Rado 1975).

From (1), differentiating $F$ with $H$ gives magnetic moment and with $E$ gives electric polarization:

$$
\begin{aligned}
& M_{i}=(-\partial F / \partial H)=M_{0}+\chi_{i j} \bar{H}_{j}+\alpha_{i j} \bar{E}_{j}, \\
& P_{i}=(-\partial F / \partial E)=P_{0}+\chi_{i j} \bar{E}_{j}+\alpha_{i j} \bar{H}_{j},
\end{aligned}
$$

where the $\alpha_{i j}$ s are the respective magnetoelectric tensors corresponding to $(\mathrm{ME})_{H}$ and $(\mathrm{ME})_{E}$. The number of components of this tensor depends upon the symmetry of the magnetic point group. In (1) the terms which occur after the $\alpha$, on further expansion of the series, would lead to higher-order magnetoelectric coefficients, viz. $\beta_{i j k}$ etc.

During the last 35 years after the discovery, linear ME effect has been observed in many compounds, including $\mathrm{Fe}_{3} \mathrm{O}_{4}$ and $\mathrm{YIG}$. Higher-order effects were also discovered experimentally. The $\mathrm{ME}$ effect is not so large in magnitude and, as mentioned earlier, the effect is restricted to insulators. From a thermodynamic point of view, the $(\mathrm{ME})_{E}$ and $(\mathrm{ME})_{H}$ effects are converse to each other and if one exists the other must also exist. However, from an experimental standpoint, the situation is not so simple.

Stimulated by the announcement by Smolenskii and Joffe (1958) of the synthesis of $\mathrm{Pb}\left(\mathrm{Fe}_{1 / 2} \mathrm{Nb}_{1 / 2}\right) \mathrm{O}_{3}$, the first antiferromagnetic ferroelectric perovskite, and in an attempt to find interesting $\mathrm{ME}$ properties, many workers tried to find antiferromagnetically and ferromagnetically ordered ferroelectrics and antiferroelectrics. Due to these efforts, a large variety of magnetoelectrically interesting compounds have been discovered, a few of which are remarkable because of interactions between spontaneous polarization and spontaneous magnetization. Special mention is to be made of the work of Schmid and his group on a number of boracites belonging to a large family of crystals with the general formula $\mathrm{Me}_{3} \mathrm{~B}_{7} \mathrm{O}_{13} \mathrm{X}$, where $\mathrm{Me}$ stands for a bivalent metal ion such as $\mathrm{Mg}, \mathrm{Cr}, \mathrm{Mn}, \mathrm{Fe}, \mathrm{Co}, \mathrm{Ni}, \mathrm{Cu}$ or $\mathrm{Zn}$, and $\mathrm{X}$ for a monovalent anion like $\mathrm{F}, \mathrm{Cl}, \mathrm{Br}$ or $\mathrm{I}$. Ismailzade et al (1980) studied a number of solid solutions based on $\mathrm{BiFeO}_{3}$ and $\mathrm{BaTiO}_{3}$, and $\mathrm{BiFeO}_{3}-\mathrm{PZT}$ for their $\mathrm{ME}$ effects.

The $\mathrm{ME}$ effect has also been reported in single-phase materials having the perovskite structure, $\mathrm{RE}$ manganates, $\mathrm{BaMF}_{4}(\mathrm{M}=\mathrm{Mn}, \mathrm{Fe}, \mathrm{Co}, \mathrm{Ni})$, inverted spinels, pseudoilmenites, $\mathrm{Cr}_{2} \mathrm{BeO}_{4}$, etc. (Smolenskii and Chupis 1984). The $\mathrm{ME}$ effect can be observed in either a single-phase material or a composite. Some single-phase materials, exhibiting simultaneous combination properties as listed below, are suitable candidates for observation of the $\mathrm{ME}$ effect. The combination properties are: ferroelectricity-ferromagnetism, ferroelectricity-ferrimagnetism, ferroelectricity-antiferromagnetism, antiferroelectricity-ferrimagnetism, antiferroelectricity-antiferromagnetism. The amount of the output signal depends on the strength of interaction between the two subsystems. Most single-phase materials studied so far have shown ME effects at low temperatures.

There is also a second approach to realize the ME conversion through composite materials. Following the concept of product properties of composites, introduced by Van Suchtelen (1972), suitable combination of piezomagnetic (phase I) and piezoelectric (phase II) phases can also give rise to the ME effect. The constituent submaterials I 
and II are coupled with respect to the $Y$ parameter, so that the output $Y$ of the $X-Y$ effect in submaterial I can act as the input parameter for the $Y-Z$ effect in submaterial II. The transfer of the $Y$ parameter from submaterial I to submaterial II can be brought aboit by the coupling mechanism

$$
\begin{aligned}
(X / Y) \cdot(Y / Z) & =X / Z, \\
(H / P) \cdot(P / E) & =H / E \rightarrow M E \text { effect }
\end{aligned}
$$

where $H$ is the applied magnetic field, $P$ the polarization and $E$ the electric field. In a composite consisting of piezomagnetic and piezoelectric phases, the applied magnetic field would induce a strain in the magnetostrictive phase, which, in turn, through mechanical coupling, causes a stress in the piezoelectric phase by which an electric field is generated.

O’Dell (1970), Skinner (1970), Freeman and Schmid (1975), Smolenskii and Chupis (1984), Tolendano et al (1985) and Siratori et al (1992) may be consulted for reviews on ME interaction phenomena in crystals.

The author's group has recently undertaken a systematic study of the preparation, characterization and detection of $(\mathrm{ME})_{H}$ output in a few single-phase and two-phase systems.

\section{Experimental}

The materials were prepared by solid-state double sintering method. The formation of phases was identified by XRD and optical microscopy. The electrical conductivity was determined by a two-probe DC technique and the dielectric data were obtained using a HP 4192 impedance analyser. The essential requirement of any material to exhibit ME output is that it should possess a high value of resistivity. The materials have to be poled electrically and magnetically before the ME measurements are made. A suitable strategy of poling has to be employed for each material. While the experimental set-up for the characterization of most of the other physical properties are well known, we restrict ourselves only to give a few details regarding the detection of the DC ME signal. The ME signal can be measured either in static fields or in dynamic fields. We have made only static measurements.

\subsection{Experimental set-up to measure $D C(M E)_{H}$}

The experimental set-up to measure ME signal is shown in figure 1 . The sample holder is made of Perspex having dimensions indicated in figure 2. Two copper electrodes were brazed to the electrical leads and were kept on either side of the poled sample. The sample is kept between the two Perspex blocks. The whole sample holder assembly was kept between the pole pieces of a DC electromagnet. All stray pick-ups have been avoided by proper grounding of the experimental set-up. The two end leads from the sample were connected to a $610 \mathrm{C}$ electrometer through a shielded cable. The measurement of output voltage is made after stabilization on the application of the magnetic field. The steady value of the voltage was noted after waiting for $30 \mathrm{~min}$. This long duration was required because of the high response time of the 


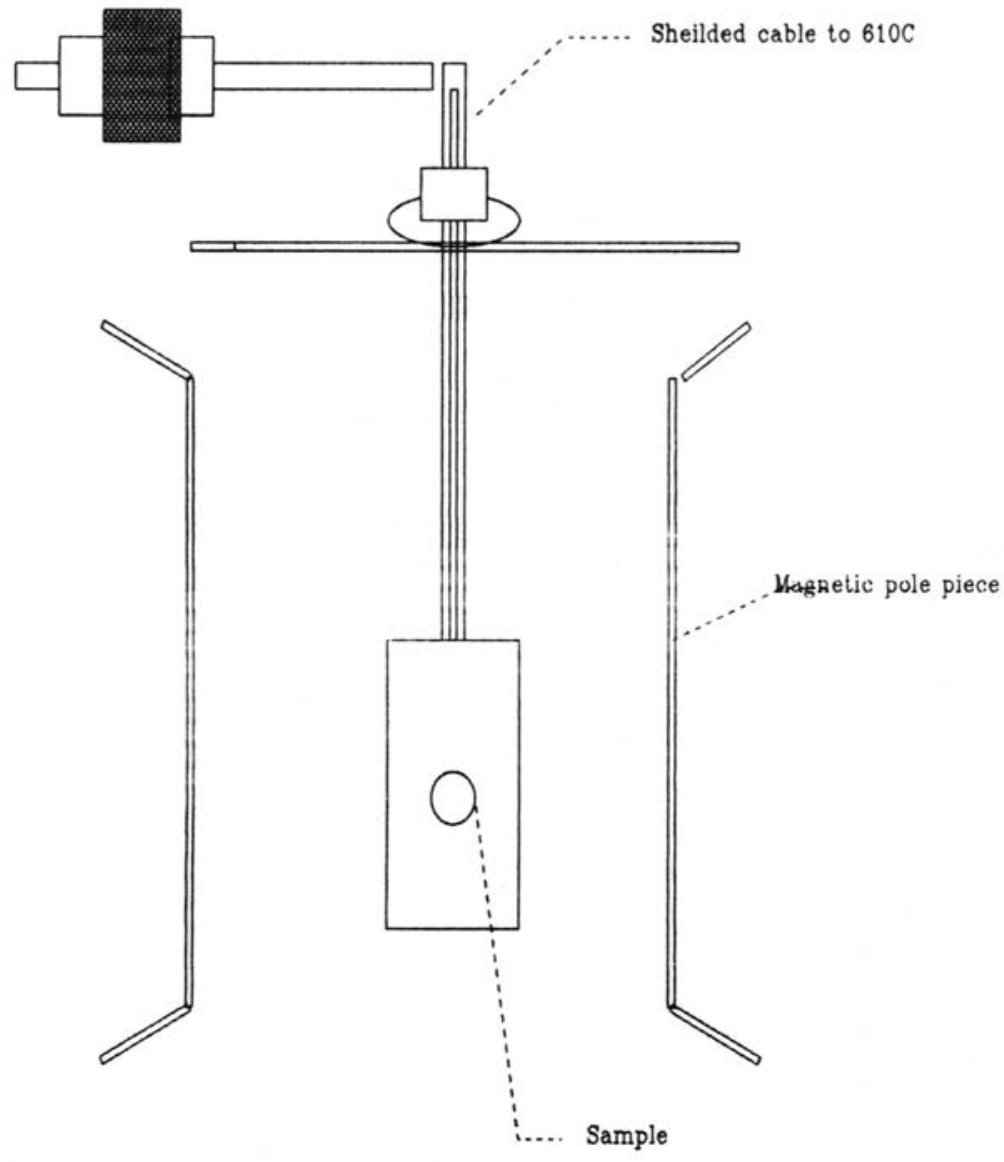

Figure 1. Set-up for measurement of MEC.
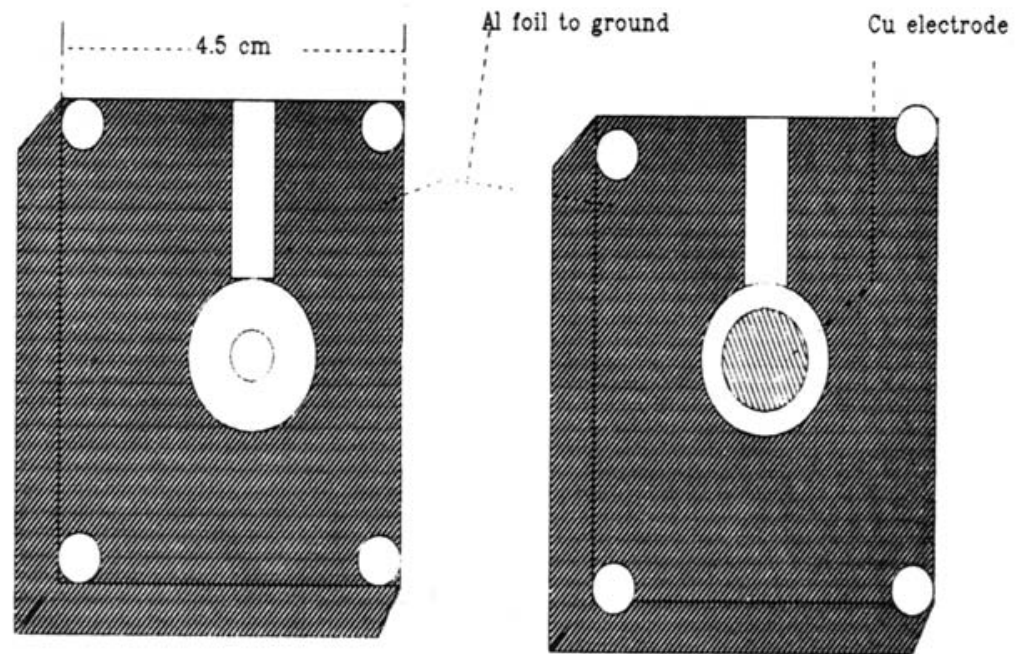

Figure 2. Sample holder for MEC measurements. 
analog meter. The output voltage developed across the sample was measured as a function of increasing and decreasing DC magnetic fields.

\section{Single-phase materials}

There is a large family of oxides with general formula $\mathbf{B i}_{2} \mathbf{M}_{n-1} \mathbf{R}_{n} \mathbf{O}_{3 n+3}$, where $n=1,2,3,4,5, \ldots$ (Aurivillius 1949 ), exhibiting interesting physical property variations and phase transitions. The cubo-octahedral $\mathrm{M}$ site accepts $\mathrm{Bi}, \mathrm{Ba}, \mathrm{K}, \mathrm{Ca}, \mathrm{Na}, \mathrm{Pb}$ and several rare-earth ions, while the smaller $\mathrm{Ti}, \mathrm{Nb}, \mathrm{Ta}, \mathrm{Fe}, \mathrm{W}, \mathrm{Mo}$ and $\mathrm{Cr}$ ions go into the octahedral $\mathrm{R}$ sites. There are more than 50 compounds in the group. The recently discovered bismuth-based superconductors also have an origin in the Aurivillius (1949) phases.

Among the different compounds that form from the general formula mentioned, those with $\mathrm{M}=\mathrm{Bi}$ and $\mathrm{R}=\mathrm{Fe} / \mathrm{Ti}$ were found to be interesting with different values of $n$ because of dielectric anomalies at high temperatures and also possible $\mathrm{ME}$ interaction. Further $\mathrm{BiFeO}_{3}$ is an interesting material because of its antiferromagnetic-ferroelectric nature and also because of the controversy about its ME output. Schmid (private communication) has reported it to be a second-order magnetoelectric material in which the first-order ME coefficient would not exist because of magnetic symmetry. But Ismailzade et al (1980) reported the presence of linear ME coefficient in a polycrystalline $\mathrm{BiFeO}_{3}$. Further, bismuth titanate is considered as a second cousin of $\mathrm{BaTiO}_{3}$ having high resistivity. The combination of these two materials would yield interesting ME materials because of the reported layer structure. We have chosen the three combinations of these two, by varying the value of $n$ in the generic formula mentioned earlier. The same formula now could be written specifically for these compounds as $\mathrm{Bi}_{4} \mathrm{Bi}_{m-3} \mathrm{Ti}_{3} \mathrm{Fe}_{m-3} \mathrm{O}_{3 m+3}$. The compounds with $m=4,5$ and 8 could be formed as $\mathrm{Bi}_{5} \mathrm{FeTi}_{3} \mathrm{O}_{15}, \mathrm{Bi}_{6} \mathrm{Fe}_{2} \mathrm{Ti}_{3} \mathrm{O}_{18}$ and $\mathrm{Bi}_{9} \mathrm{Fe}_{5} \mathrm{Ti}_{3} \mathrm{O}_{27}$ respectively, whereas compounds with $m=6$ and 7 cannot be formed. These three compounds have been reported to show simultaneous existence of ferroelectric and magnetic nature up to very high temperatures. This is the precondition for the material to be magnetoelectric. The preparation and characterization of $\mathrm{Bi}_{5} \mathrm{FeTi}_{3} \mathrm{O}_{15}$ will be discussed in some detail and for the others only the final results will be presented (Singh et al 1994a).

\section{1 $\mathrm{Bi}_{5} \mathrm{FeTi}_{3} \mathrm{O}_{15}$ and related materials}

The compound was formed by solid-state reaction method by taking $\mathrm{Bi}_{2} \mathrm{O}_{3}, \mathrm{Fe}_{2} \mathrm{O}_{3}$ and $\mathrm{TiO}_{2}$ in molar proportions. They were presintered at $850^{\circ} \mathrm{C}$ for $2 \mathrm{~h}$ and later final-sintered at $1050^{\circ} \mathrm{C}$ for $2 \mathrm{~h}$. The XRD pattern obtained for these samples was compared with that of Ismailzade et al (1967). The average density measured was $7.87 \mathrm{~g} / \mathrm{cm}^{3}$. X-ray density was found to be $8.03 \mathrm{~g} / \mathrm{cm}^{3}$ indicating that the pellets formed had negligible porosity. The samples were essentially poled at $150^{\circ} \mathrm{C}$ in an electric field of $10 \mathrm{kV} / \mathrm{cm}$. The dielectric measurements were performed using a $\mathrm{HP}$ impedance analyser in the temperature range $\mathrm{RT}$ to $850^{\circ} \mathrm{C}$ at a fixed frequency of $10 \mathrm{kHz}$ in order to avoid the effect of space charge polarization, if any. A hump around $750^{\circ} \mathrm{C}$ was observed, but no sharp transition in the dielectric measurement was observable.

The magnetoelectric measurements were performed on this material by selecting 


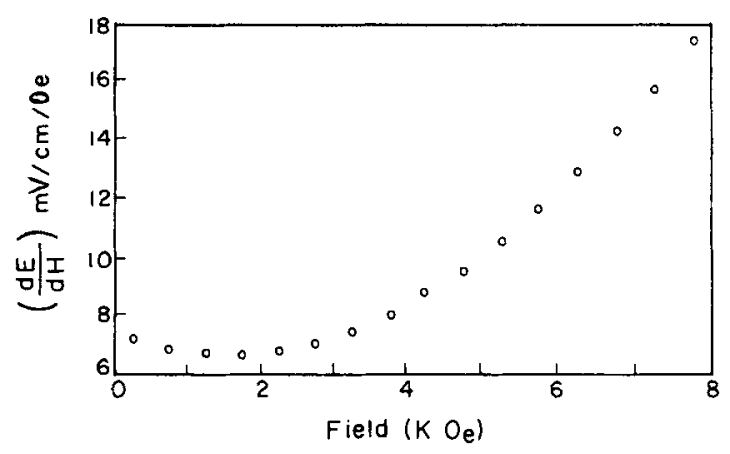

Figure 3. $\mathrm{d} E / \mathrm{d} H$ vs field of $\mathrm{Bi}_{5} \mathrm{FeTi}_{3} \mathrm{O}_{15}$.

a disk of $1 \mathrm{~mm}$ thickness. The sample was electrically poled as mentioned above and was also poled magnetically in a field of $9 \mathrm{kOe}$. The magnetoelectric signal was obtained by measuring the voltage developed across the sample as a function of applied DC magnetic field up to $8 \mathrm{kOe}$.

The variation of $\mathrm{d} E / \mathrm{d} H$ vs $H$ is shown in figure 3. The maximum value of $\mathrm{d} E / \mathrm{d} H$ observed was $17 \mathrm{mV} / \mathrm{Oe} / \mathrm{cm}$ at $8 \mathrm{kOe}$. It was also observed that when the magnetic field was reduced, the electric polarization did not decrease indicating thereby that the electric charges have been locked at the grain boundaries. Heating of such a sample brought the polarization to zero indicating that this material could be an example of an electret. The measurement of ME coefficient in this sample was made possible due to its high value of resistivity, viz. $5.8 \times 10^{11} \mathrm{ohm}-\mathrm{cm}$ at room temperature. The polarization induced could be due to the displacement of $\mathrm{Fe}$ ions, thereby changing the ionic polarizability or creating quasi-permanent dipoles. The complete data for this sample are given in table 1 (Singh et al 1994a).

Following a similar preparation technique, $\mathrm{Bi}_{6} \mathrm{Fe}_{2} \mathrm{Ti}_{3} \mathrm{O}_{18}$ and $\mathrm{Bi}_{9} \mathrm{Fe}_{5} \mathrm{Ti}_{3} \mathrm{O}_{27}$ were also prepared. These two compounds also showed high value of resistivity. The $\mathrm{ME}$ coefficient in $\mathrm{Bi}_{6} \mathrm{Fe}_{2} \mathrm{Ti}_{3} \mathrm{O}_{18}$ was found to be $3.2 \mathrm{mV} / \mathrm{cm} / \mathrm{Oe}$ at $4 \mathrm{kOe}$ (Singh et al 1994b) which is less than that of $\mathrm{Bi}_{5} \mathrm{FeTi}_{3} \mathrm{O}_{15}$. The $\mathrm{ME}$ measurements in $\mathrm{Bi}_{9} \mathrm{Fe}_{5} \mathrm{Ti}_{3} \mathrm{O}_{27}$ (Singh, unpublished) did not yield any result indicating thereby that $\mathrm{ME}$ interactions in these samples are very weak. Therefore from table 1 one could observe that, as the $\mathrm{Fe}$ content increased, the $\mathrm{ME}$ interaction decreased, thereby affecting the ME coefficient.

We have reinvestigated $\mathrm{BiFeO}_{3}$ which also has an impurity phase of $\mathrm{Bi}_{2} \mathrm{Fe}_{4} \mathrm{O}_{9}$. The resistivity of our sample was however very large $\left(10^{12} \mathrm{ohm}-\mathrm{cm}\right)$ compared to that reported by Schmid (1994). After usual electrical and magnetic poling, DC ME measurements were performed. The ME coefficient obtained in the sample was of first order as reported by Ismailzade's (1967) group. The ME coefficient observed was however lower than that of four-layer and five-layer compounds but measurable, and is equal to $64 \mu \mathrm{V} / \mathrm{cm} / \mathrm{Oe}$ at $9.5 \mathrm{kOe}$. Further studies on $\mathrm{BiFeO}_{3}$ are in progress.

\section{Two-phase materials}

Boomgaard et al (1974) prepared composites of piezoelectric and piezomagnetic phases and detected the magnetoelectric output. The piezomagnetic phase chosen was 


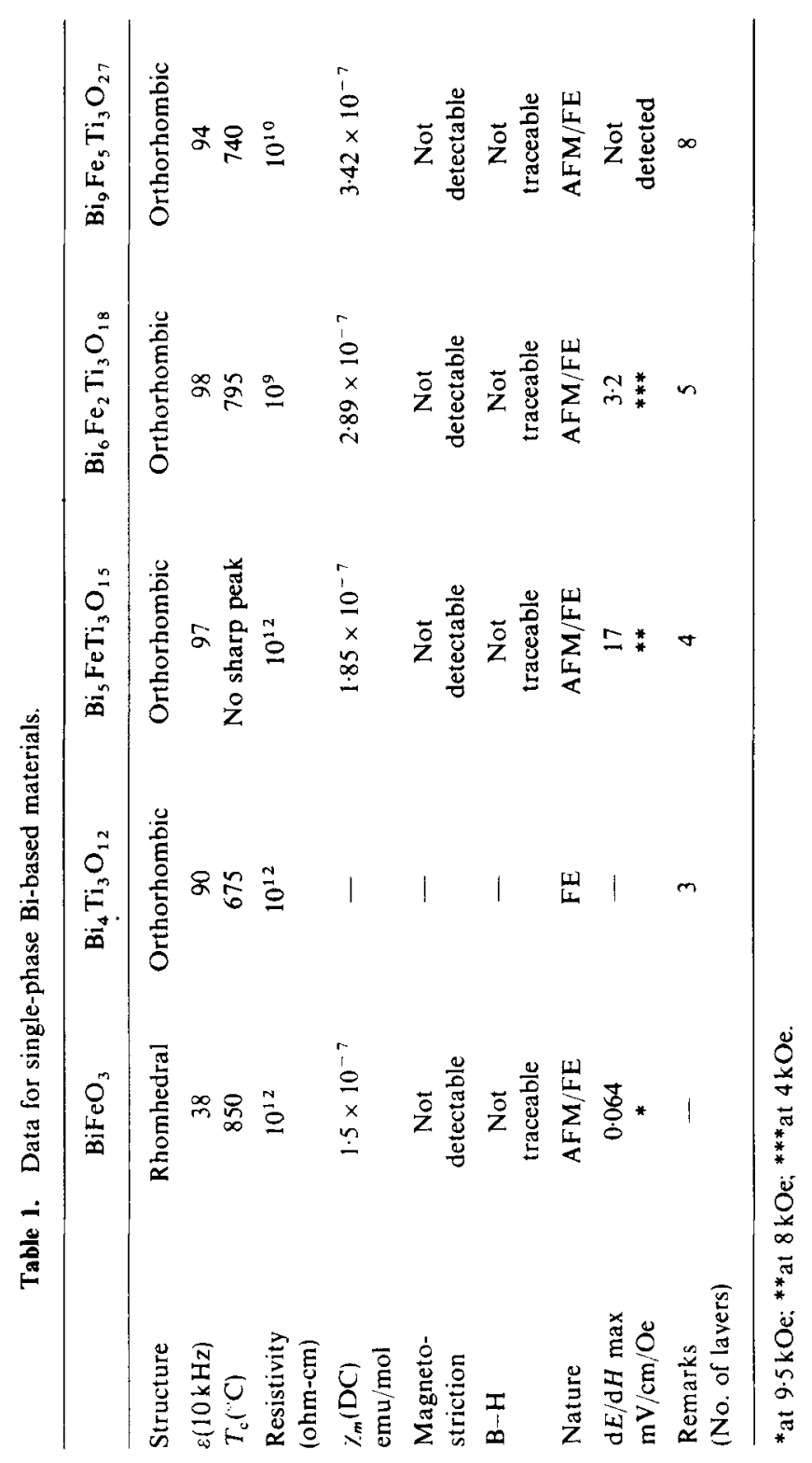


$\mathrm{Ni}(\mathrm{Co}, \mathrm{Mn}) \mathrm{Fe}_{2} \mathrm{O}_{4}$ and the piezoelectric phase was $\mathrm{BaTiO}_{3}$. They observed the higher $\mathrm{ME}$ conversion of $130 \mathrm{mV} / \mathrm{cm} / \mathrm{Oe}$ in unidirectionally cooled composite of $60 \%$ $\mathrm{Ni}(\mathrm{Co}, \mathrm{Mn}) \mathrm{Fe}_{2} \mathrm{O}_{3}-40 \% \mathrm{BaTiO}_{3}$ than in the same composite prepared by double sintering method. They have also studied the dependence of $\mathrm{d} E / \mathrm{d} H$ on various process parameters, compositions, and particle sizes of the composites. Experimentally it is easier to prepare composites by double-sintering process than the unidirectional cooling. The existence of a eutectic point or a eutectoid phase is a prerequisite for unidirectional cooling. The following are the advantages of solid-state sintering: (a) free choice of mole ratio of constituent phases and sintering temperatures, (b) independent choice of grain size of each phase.

To realize higher output of ME conversion in composite materials the following guidelines are to be kept in mind (Boomgaard et al 1977).

(i) The two phases must be in equilibrium.

(ii) Mechanical contact between grains must be perfect.

(iii) The value of magnetostriction coefficient of piezomagnetic phase must be high.

(iv) The value of piezoelectric coefficient of the piezoelectric phase must be high.

(v) The accumulated charges must not leak through the piezomagnetic phase. Hence this phase should have resistivity $>10^{8} \mathrm{ohm}-\mathrm{cm}$.

(vi) $T_{c} \gg R_{t}$ to facilitate poling and the relaxation time for charge compensation is to be longer.

(vii) Proper poling strategy is to be adopted for the material to show higher ME conversion.

We have studied composites of $\mathrm{CoFe}_{2} \mathrm{O}_{4}-\mathrm{BaTiO}_{3}$ (Hanumaiah et al 1994), $\mathrm{NiFe}_{2} \mathrm{O}_{4}-\mathrm{BaTiO}_{3}, \mathrm{LiFe}_{5} \mathrm{O}_{8}-\mathrm{BaTiO}_{3}$ (Suryanarayana et al 1994), $\mathrm{CoFe} \mathrm{O}_{4}$ $\mathrm{Bi}_{4} \mathrm{Ti}_{3} \mathrm{O}_{12}$. The $\mathrm{CoFe} \mathrm{O}_{2} \mathrm{O}_{4}-\mathrm{BaTiO}_{3}$ composites have been prepared by solid-state double-sintering route. The samples were characterized by XRD. The sign of ME conversion in the samples depended on the polarization direction of the ferroelectric phase. Therefore the electrical poling was done for all samples at $150^{\circ} \mathrm{C}$ which is $30^{\circ} \mathrm{C}$ above the ferroelectric transition temperature of $\mathrm{BaTiO}_{3}$. At room temperature the applied electric field was $7.5 \mathrm{kV} / \mathrm{cm}$. The field started decreasing at around $90^{\circ} \mathrm{C}$ and was about $3-5 \mathrm{kV} / \mathrm{cm}$ at $150^{\circ} \mathrm{C}$ depending on the composition. The samples were kept at this temperature for $30 \mathrm{~min}$ and were cooled to room temperature in the presence of the external field. Later the samples were subjected to magnetic poling in a DC magnetic field.

The dielectric permittivity $\varepsilon_{r}$ of all the composites of cobalt ferrite-barium titanate have been measured in the temperature range room temperature to $130^{\circ} \mathrm{C}$, for which silver-coated pellets were used. Using a HP 4192A impedance analyser, the dielectric measurements were carried out at $10 \mathrm{kHz}$. In these composites, with increasing concentration of $\mathrm{BaTiO}_{3}$ the $T_{\mathrm{c}}$ was found to increase from $115^{\circ} \mathrm{C}$ to $120^{\circ} \mathrm{C}$. The ME coefficient $(\mathrm{d} E / \mathrm{d} H)$ of the composites, which is the product of piezomagnetic deformation and the piezoelectric generation, largely depends on the electrical resistivity of the sample and the mechanical coupling between the two phases.

We have measured ME conversion for three compositions of $\mathrm{CoFe}_{2} \mathrm{O}_{4}-\mathrm{BaTiO}_{3}$ as a function of $\mathrm{DC}$ magnetic field. The $\mathrm{ME}$ conversion factor for different magnetic fields from $0.1 \mathrm{kOe}$ to $2 \mathrm{kOe}$ was determined by measuring the voltage across the sample with a $610 \mathrm{C}$ Keithley electrometer. Figure 4 shows the typical dependence of magnetoelectric conversion on magnetic field for three composites studied. The 


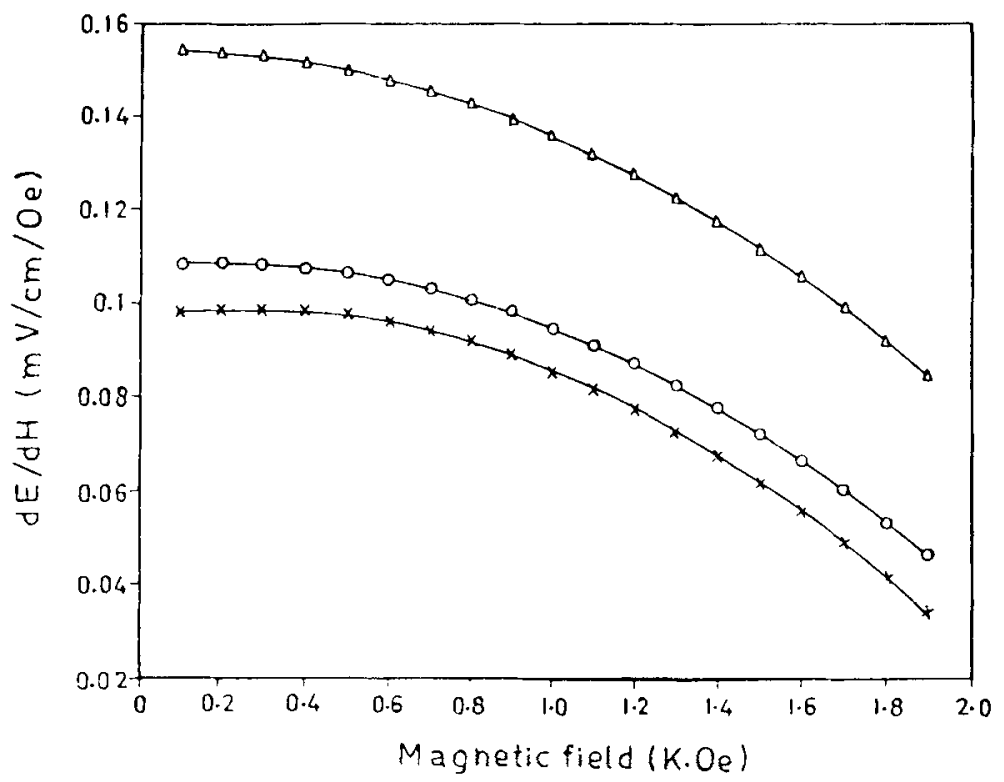

Figure 4. $\mathrm{d} E / \mathrm{d} H$ vs field of cobalt ferrite-barium titanate composite. $\left(\times, 60 \% \mathrm{CoFe}_{2} \mathrm{O}_{4}-40 \%\right.$ $\mathrm{BaTiO}_{3} ; \mathrm{O}, 50 \% \mathrm{CoFe}_{2} \mathrm{O}_{4}-50 \% \mathrm{BaTiO}_{3}: \Delta, 40 \% \mathrm{CoFe}_{2} \mathrm{O}_{4}-60 \% \mathrm{BaTiO}_{3}$ ).

maximum value of $\mathrm{d} E / \mathrm{d} H$ observed in a composition containing $60 \mathrm{~mole} \%$ of $\mathrm{BaTiO}_{3}$ is $160 \mu \mathrm{V} / \mathrm{cm} / \mathrm{Oe}$. From figure 4 it is seen that the value of $\mathrm{d} E / \mathrm{d} H$ decreases with increasing magnetic field beyond 600 Oe for all three composites. As already mentioned, the magnetoelectric conversion is the result of piezomagnetic strain in spinel phase which creates piezoelectric charge in the ferroelectric phase and hence the latter would depend upon the variation of piezomagnetic coefficient with intensity of magnetic field. In the spinels, the magnetostrictive coefficient reaches a saturation at a certain value of magnetic field. In the case of $\mathrm{CoFe}_{2} \mathrm{O}_{4}$ the magnetostriction as well as the intensity of the magnetic field reaches saturation around $600 \mathrm{Oe}$ (Cullity 1972). Therefore, beyond this field, the magnetostriction and the strain thus produced would also produce a constant electric field in the piezoelectric phase, hence making the $\mathrm{d} E / \mathrm{d} H$ decrease with increasing magnetic field. Our figures for $\mathrm{CoFe}_{2} \mathrm{O}_{4}-\mathrm{BaTiO}_{3}$ composites prepared by solid-state route are much lower than those of Boomgaard et al (1974). The lower values obtained in this work may be attributed to the spinel phase having resistivity less by about 4-5 orders of magnitude than the piezoelectric phase. Presumably the ferrite phase offers a leakage path for the charges developed across the piezoelectric phase.

\section{1 $\mathrm{LiFe}_{5} \mathrm{O}_{8}-\mathrm{BaTiO}_{3}$}

Velleaud et al (1982) reported that $\mathrm{LiFe}_{5} \mathrm{O}_{8}$ single crystal shows magnetoelectric conversion at $6 \mathrm{~K}$. They observed second-order magnetoelectric effect along (001) direction at $6 \mathrm{~K}$. We have prepared composites of $\mathrm{LiFe}_{5} \mathrm{O}_{8}-\mathrm{BaTiO}_{3}$ to look for possible $\mathrm{ME}$ conversion at room temperature. The composites have been prepared by solid-state double-sintering method in which there was no detectable ME signal. 
However, in a second batch of preparation; $\mathrm{LiFe}_{5} \mathrm{O}_{8}$ was prepared by sol-gel method and composites of $\mathrm{LiFe}_{5} \mathrm{O}_{8}-\mathrm{BaTiO}_{3}$ were made. The composites prepared from the sol-gel LiFe ${ }_{5} \mathrm{O}_{8}$ exhibited a high resistivity and comparatively high dielectric constant. The magnetoelectric conversion also could be detected. In a recent communication from our laboratory the details of this study have been reported (Suryanarayana et al 1992). In figure 5 we present the data for $\mathrm{d} E / \mathrm{d} H$. In table 2 we summarize the results.

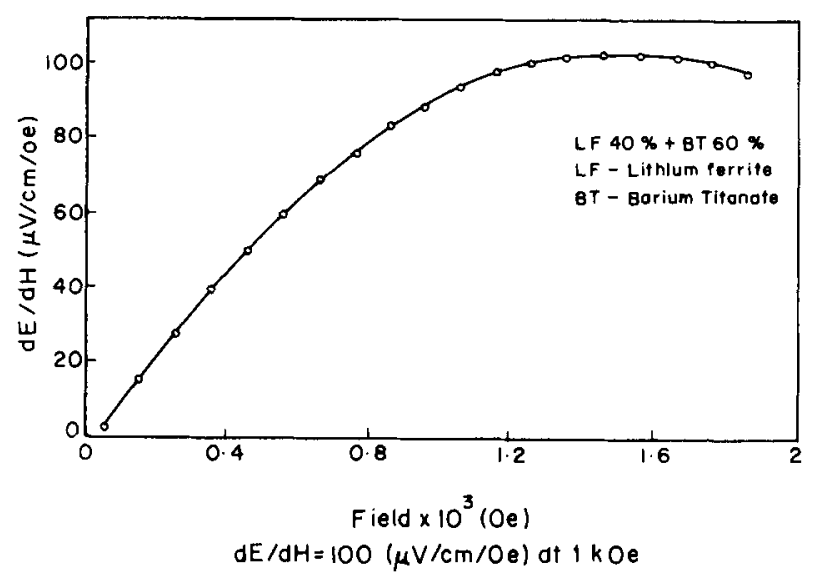

Figure 5. $\mathrm{d} E / \mathrm{d} H$ vs field of lithium ferrite-barium titanate composite.

Table 2. Data for composites

\begin{tabular}{|c|c|c|c|c|c|c|}
\hline \multicolumn{3}{|c|}{ Composition } & $\varepsilon$ & $\begin{array}{l}\text { Resistivity } \\
\text { (ohm-cm) }\end{array}$ & $\begin{array}{c}T_{\mathrm{c}} \\
\left({ }^{\circ} \mathrm{C}\right)\end{array}$ & ME \\
\hline \multicolumn{7}{|c|}{ Solid-state route } \\
\hline $\mathrm{CF}$ & + & BT & & & & \\
\hline 60 & & 40 & 209 & $10^{8}$ & 115 & $100 \mu \mathrm{V} / \mathrm{cm} / \mathrm{Oe}$ \\
\hline 50 & & 50 & 98 & $10^{8}$ & 117 & $109 \mu \mathrm{V} / \mathrm{cm} / \mathrm{Oe}$ \\
\hline 40 & & 60 & 144 & $10^{9}$ & 120 & $160 \mu \mathrm{V} / \mathrm{cm} / \mathrm{Oe}$ \\
\hline LF & + & BT & & & & \\
\hline 60 & & 40 & 540 & $10^{8}$ & 50 & No signal \\
\hline 50 & & 50 & 815 & $10^{9}$ & 50 & No signal \\
\hline 40 & & 60 & 890 & $10^{10}$ & 50 & No signal \\
\hline \multicolumn{7}{|c|}{ (Sol gel) } \\
\hline 60 & & 40 & 80 & $10^{10}$ & 92 & No signal \\
\hline 40 & & 60 & 102 & $10^{9}$ & 102 & $100 \mu \mathrm{V} / \mathrm{cm} / \mathrm{Oe}$ \\
\hline NF & + & BT & & & & \\
\hline 60 & & 40 & 620 & $10^{7}$ & 107 & $300 \mu \mathrm{V} / \mathrm{cm} / \mathrm{Oe}$ \\
\hline 40 & & 60 & 718 & $10^{8}$ & 99 & $450 \mu \mathrm{V}, \mathrm{cm} / \mathrm{Oe}$ \\
\hline $\mathrm{CF}$ & + & $\mathrm{BIT}(\mathrm{SS})$ & & & & \\
\hline 50 & & 50 & 90 & $10^{9}$ & 675 & $120 \mu \mathrm{V} / \mathrm{cm} / \mathrm{Oe}$ \\
\hline
\end{tabular}

NF, Nickel ferrite; BT, barium titanate; LF, lithium ferrite; CF, cobalt ferrite; BIT, bismuth titanate. 
Wood and Austin (1974) indicated possible applications of magnetoelectric crystals as well as the characteristics of over 15 devices whose operation range varies from audio to optical frequency, including modulators, switches, phase invertors, rectifiers, etc. Materials showing ME conversion can also be used as thin-film wave guides in integral optics and fibre communication technology.

The research on ME effect seems to be less popular among physicists in recent times compared to the works of the first generation. Though the magnitude of the effect in terms of the output is small, it gives a unique technique for the study of the properties of materials both in single-phase and composite form. There are many materials exhibiting simultaneous electric polarization and magnetic ordering which may be good candidates for the study of ME interactions. Here is an area of research for generations of materials scientists to involve themselves in materials engineering with a view to achieve higher yield of $\mathrm{ME}$ coefficients to explore the possibility to identify suitable materials for yet unexplored applications. Our group is presently engaged in such activity.

\section{Acknowledgements}

The author received funding for his research from various organizations, viz. DST, DRDO, CSIR and UGC. He thanks his teachers and associates who helped him build up a research group for the study of a variety of thermophysical properties of materials. Special mention is made of his teacher late Prof. V T Deshpande. He benefitted from the collaboration of his colleagues Prof. $T$ Bhimasankaram and Dr G S Kumar, who are actively involved in this work. He thanks his research students Mr R S Singh, Mrs P Sarah, Mr A Hanumiah and Mr A R James, who are involved in this work, and other research students for helping him build up a Materials Research Laboratory at the Department of Physics, Osmania University. It is a pleasure to thank Prof. H Schmid, University of Geneva, for discussions; Dr P Rama Rao, Secretary, DST who enthused and initiated him to take up work on nonstructural composite materials: Dr V N Mulay of IICT, who was associated in the sol-gel process of preparing the materials.

\section{References}

Astrov D N 1960 J. Exp. Theor. Phys. (USSR) 38984

Astrov D N 1961 J. Exp. Theor. Phys. (USSR) 401035

Aurivillius B 1949 Arki Kemi 1,463,499

Boomgaard J V D, Terrel D R, Born R A J and Giller H F J I 1974 J. Mater. Sci. 91705

Cullity B D 1972 Introduction to magnetic materials (New York: Addison-Wesley)

Curie P 1894 J. Phys. 3e serie 3393

Dzyaloshinskii I E 1959 J. Exp. Theor. Phys. (USSR) 37881

Folen V J, Rado G T and Stalder E W 1961 Phys. Rev. Lett. 607

Freeman A J and Schmid H (eds) 1975 Magnetoelectric interaction phenomena in crystals (London: Gordon and Breach)

Hanumiah A, Bhimasankaram T, Suryanarayana S V and Kumar G S 1994 Bull. Mater. Sci. (in press) Ismailzade I H 1967 Sor: Phys. Crystallogr. 12 no. 3

Ismailzade I H, Nesternko V I, Mirishli F A and Rustamov P G 1980 Phys. Status Solidi 5799

Landau L D and Lifshitz E M 1957 Elektrodynamica sploshnuikh Sred, Gosudarstvennoe Izdatel'stvo Fiziko-Matematichesko Literatury, Moscow 
O'Dell T H 1970 Electrodynamics of magnetoelectric media (London: North Holland)

Rado G T 1975 in Magnetoelectric interaction phenomena in crystals (ed.) A J Freeman and H Schmid (London: Gordon and Breach) p. 3

Schmid H 1965a J. Phys. Chem. Solids 26973

Schmid H 1965b Solid State Commun. 3327

Schmid H 1984 Ferroelectrics 55298

Singh R S, Bhimasankaram T, Kumar G S and Suryanarayana S V 1994a Solid State Commun. 91567 Singh R S, Bhimasankaram T, Kumar G S and Suryanarayana S V 1994b Int. J. Mod. Phys. B(in press)

Siratori K, Kohn K and Kita E 1992 Acta Phys. Polonica A81 4

Skinner S M 1970 IEEE Trans. Parts. Mater. Packaging PMP-6 68

Smolenskii G A and Chupis I E 1984 Problems in solid state physics (Moscow: Mir Publishers)

Smolenskii G A and Joffe V A 1958 Communications de Colloquue International

Suryanarayana S V, Bhimasankaram T, Sarah P, Singh R S and Mulay V N 1994 Proc. of the Vth Asia-Pacific Physics Conf. (Singapore: World Scientific) vol. 2 p. 738

Toledano P, Schmid H, Clin M and Rivera P 1985 Phys. Rev. B32 6006

Van Suchetelen J 1972 Philips Res. Rep. 2728

Velleaud G, Mercier M and Aubert G 1982 Solid State Commun. 441387

Wood E and Austin A E 1974 Int. J. Magnet. 5303 